\title{
Comparative spatial spread overtime of Zucchini Yellow Mosaic Virus (ZYMV) and Watermelon Mosaic Virus (WMV) in fields of transgenic squash expressing the coat protein genes of ZYMV and WMV, and in fields of nontransgenic squash
}

\author{
Ferdinand E. Klas · Marc Fuchs • \\ Dennis Gonsalves
}

Received: 17 August 2005/ Accepted: 12 April 2006/Published online: 13 July 2006

(C) Springer Science+Business Media B.V. 2006

\begin{abstract}
The spatial and temporal patterns of aphid-vectored spread of Zucchini Yellow Mosaic Virus (ZYMV) and Watermelon Mosaic Virus (WMV) were monitored over two consecutive years in plantings of nontransgenic and transgenic squash ZW-20H (commercial cv. Freedom II) and ZW-20B, both expressing the coat protein genes of ZYMV and WMV. All test plants were surrounded by nontransgenic plants that were mechanically inoculated with ZYMV or WMV, and served as primary virus source. Across all trials, none of the transgenic plants exhibited systemic symptoms upon infection by ZYMV and WMV but a few of them developed localized chlorotic dots and/or blotches, and had low mixed infection rates [4\% (6 of 139) of ZW-20H and 9\% (13 of 139) of ZW-20B], as shown by ELISA. Geostatistical analysis of ELISA positive transgenic plants indicated, (i) a lack of spatial relationship on spread of ZYMV and WMV for
\end{abstract}

F. E. Klas $(\bowtie) \cdot$ M. Fuchs · D. Gonsalves

Department of Plant Pathology, Cornell University,

New York State Agricultural Experiment Station,

Geneva, NY 14456, USA

e-mail: fklas@yahoo.com

F. E. Klas

Anton de Kom Universiteit van Suriname, Faculteit der Technologische Wetenschappen,

Universiteitscomplex Leysweg, Building XVII, POB

9212, Paramaribo, Suriname
ZW-20H with flat omnidirectional experimental semivariograms that fitted poorly theoretical models, and (ii) some extent of spatial dependence on ZYMV spread for ZW-20B with a well structured experimental semivariogram that fitted poorly theoretical models during the first but not the second growing season. In contrast, a strong spatial dependence on spread of ZYMV and WMV was found for nontransgenic plants, which developed severe systemic symptoms, had prevalent mixed infection rates $(62 \%, 86$ of 139$)$, and well-defined omnidirectional experimental semivariograms that fitted a spherical model. Geostatistical data were sustained by virus transmission experiments with Myzus persicae in screenhouses, showing that commercial transgenic squash ZW-20H alter the dynamics of ZYMV and WMV epidemics by preventing secondary plant-to-plant spread.

Keywords Transgenic squash $\cdot \mathrm{ZYMV}$ and WMV $\cdot$ Resistance $\cdot$ Spatial and temporal spread . Geostatistical analysis $\cdot$ Epidemiology

\section{Introduction}

The potyviruses Zucchini Yellow Mosaic Virus (ZYMV) and Watermelon Mosaic Virus (WMV) cause devastating epidemics and severe yield losses in cucurbit crops, including squash 
(Blancard et al. 2004; Zitter et al. 1996). ZYMV and WMV have a worldwide distribution and are transmitted in a noncirculative, nonpersistent manner by several aphid species (Castle et al. 1992). Mixed infections by ZYMV and WMV are often detected in squash fields (Davis and Mizuki 1987; Ullman et al. 1991).

Transgenic crookneck squash ZW-20 express the coat protein (CP) genes of ZYMV and WMV and are highly resistant to single and mixed infections by ZYMV and/or WMV (ArceOchoa et al. 1995; Clough and Hamm 1995; Fuchs and Gonsalves 1995; Tricoli et al. 1995). Plants of transgenic line ZW-20, unlike nontransgenic controls, do not develop severe systemic symptoms upon infection by ZYMV and WMV but occasionally localized mild symptoms that consist of chlorotic dots and/or blotches on a few leaves. A 1993 field trial showed the presence of ZYMV and WMV in leaves with chlorotic dots of $56 \%$ of the transgenic plants but not in asymptomatic leaves even 10 weeks after transplanting (Fuchs and Gonsalves 1995). Despite localized mild foliar symptoms, fruits of transgenic plants are symptomless and of marketable quality (Arce-Ochoa et al. 1995; Clough and Hamm 1995; Fuchs and Gonsalves 1995; Tricoli et al. 1995).

During the development process of transgenic line ZW-20, two groups of plants were identified based on the type of mild symptoms and the number of WMV CP gene inserts (Tricoli et al. 1995). The first group included plants that were symptomless or eventually developed chlorotic dots upon infection by ZYMV or WMV. These plants contained the $\mathrm{H}$ insert of the WMV CP gene and were labeled $\mathrm{ZW}-20 \mathrm{H}$ (Tricoli et al. 1995). The second group included plants that developed chlorotic dots and blotches upon infection by ZYMV or WMV and lacked the $\mathrm{H}$ insert; these were labeled ZW-20B (Tricoli et al. 1995). Despite a differential foliar reaction to ZYMV and WMV, fruits of both transgenic lines ZW-20H and ZW-20B are asymptomatic and of marketable quality even when plants are exposed to severe disease pressure (Arce-Ochoa et al. 1995; Clough and Hamm 1995; Fuchs and Gonsalves 1995; Tricoli et al. 1995). Transgenic line $\mathrm{ZW}-20 \mathrm{H}$, which is expressing the highest level of resistance, was used as one of the parents for the development of the commercial F1 hybrid cultivar Freedom II (Tricoli et al. 1995), the first virusand disease-resistant transgenic crop cleared for commercial use in the United States (Medley 1994).

The reaction of transgenic crops, including transgenic squash $\mathrm{ZW}-20$, to virus infection is usually based on a comparative analysis of disease incidence in transgenic versus nontransgenic control cultivars. This approach relies on differences in the percentage, mean, and/or variance of infected plants between two genetically distinct cultivars (Clough and Hamm 1995; Fuchs and Gonsalves 1995; Fuchs et al. 1998a, b 1999; Gonsalves et al. 1992; Kanieswki et al. 1990; Malnoe et al. 1994; Steinlage et al. 2002). It is powerful to evaluate the level of resistance, however, it does not provide information on the spatial relationship among test plants nor does it illustrate disease progress in space. Geostatistical analysis is another approach to evaluate disease incidence in two genetically distinct cultivars. This approach takes into account the position of a plant in space and quantifies the degree of spatial dependence of a test plant with its neighbors (Camann et al. 1995; Chellemi et al. 1988; Gottwald 1992a, b; Gray et al. 1986; Larkin et al. 1995; Lecoustre et al. 1989; Madden et al. 1987; Stein et al. 1994). Analysis of spatial and temporal spread of viruses is important in understanding the dynamics of viral epidemics in conventional (Habili and Nutter 1997; Journel 1987; Lecoustre et al. 1989; Tanne et al. 1996) and transgenic (Steinlage et al. 2002) crops.

Limited information, if any, is available on the comparative incidence of ZYMV and WMV in time and space in fields of transgenic squash ZW-20 and nontransgenic squash. We addressed these issues in commercial-type small-scale plantings by using geostatistical analysis. The main objective of our study was to examine the effect of transgenic squash ZW-20 on the dynamics of aphid-vectored spread of ZYMV and WMV. Our findings provide new insights into the epidemiological benefits of commercial virus-resistant transgenic squash. These features have significant implications in environmental safety assessment. 


\section{Materials and methods}

Plant material

Transgenic crookneck squash line ZW-20 was developed by Agrobacterium tumefaciens-mediated transformation using the binary vector pPRBN-ZYMV72/WMVBN22 (Tricoli et al. 1995). This vector contains the coat protein (CP) genes of ZYMV and WMV, and the marker gene neomycin phosphotransferase (NPT II). The resistance of transgenic line $\mathrm{ZW}-20$ to single and mixed infection by ZYMV and WMV is well documented (Arce-Ochoa et al. 1995; Clough and Hamm 1995; Fuchs and Gonsalves 1995; Tricoli et al. 1995). Transgenic ZW-20H and ZW-20B plants, which derive from ZW-20, differ in the type of mild symptoms expressed upon infection by ZYMV or WMV and in the number of WMV CP gene inserts (Tricoli et al. 1995). Transgenic hybrids of both lines were used in this study. These hybrids resulted from crosses of transgenic plants, which were homozygous for the two CP transgenes, and an untransformed parent.

The two commercial nontransgenic cultivars Pavo and President, which are susceptible to ZYMV and WMV, were used as controls in open field experiments and as recipients in aphidmediated virus transmission experiments, respectively. Transgenic and nontransgenic hybrids used in open field experiments had the same genetic background.

\section{Experimental layout}

Field trials were carried out at the Crittenden farm of the New York State Agricultural Experiment Station in Geneva, NY. In 1994, experiments were conducted under permits issued by APHIS-USDA. In 1995, permits were not required because transgenic line $\mathrm{ZW}-20$ was deregulated in December of 1994 (Medley 1994). Six squash field plots were established over the two consecutive years. In 1994, two field plots were planted: One with transgenic ZW-20B plants and one with nontransgenic control plants. The two field plots were established $20 \mathrm{~m}$ apart with 8 rows, $2 \mathrm{~m}$ apart, and 27 plants per row at a $1 \mathrm{~m}$ within-row distance. In 1995, four field plots were planted: Two with transgenic plants (one with ZW-20H and one with ZW-20B) and two with nontransgenic control plants. The four field plots were established $20 \mathrm{~m}$ apart and consisted of 10 rows with 20 plants each. The between- and within-row distances were the same as in 1994.

The six field plots were surrounded by a single row of nontransgenic controls, which were mechanically inoculated with ZYMV or WMV prior to transplanting (Fuchs and Gonsalves 1995), and used as primary virus inocula for aphid-vectored infections. Mechanically inoculated plants were transplanted in alternating groups of four ZYMV-infected and four WMVinfected plants. No insecticide was used in open field experiments for efficient virus spread by indigenous aphid populations.

Analysis of disease progress

Virus incidence was monitored on test plants by visual observation of symptoms every 3-4 days and by double antibody sandwich (DAS) enzymelinked immunosorbent assay (ELISA) using $\gamma$-globulins specific to ZYMV and WMV that were produced in our laboratory. Tissue from leaves in position 3-5 at the apical end was sampled for each test plant at three different dates during each growing season, and subsequently tested in DAS-ELISA, as described (Fuchs and Gonsalves 1995). Samples were considered positive if their optical density readings at $405 \mathrm{~nm}$ $\left(\mathrm{OD}_{405} \mathrm{~nm}\right)$ were at least twice the values of healthy nontransgenic controls. Data on symptom development overtime, symptom type, and DASELISA scores were subsequently mapped. Maps indicated the location of each test plant in the field by using row numbers as horizontal axes $(x)$ and plant location within rows as vertical axes $(y)$. Maps were composed for symptomatic plants and for plants that reacted positively for ZYMV and/ or WMV in DAS-ELISA. Based on the severity of symptoms and DAS-ELISA scores, test plants were grouped into four distinct categories. The first category consisted of symptomless plants that were negative for ZYMV and/or WMV in ELISA. The second category had plants with localized mild symptoms that were negative for ZYMV and/or WMV in ELISA. The third 
category consisted of plants with mild symptoms that were positive for ZYMV and/or WMV in ELISA. The last category had plants with severe systemic symptoms that were positive for ZYMV and/or WMV in ELISA.

\section{Geostatistical analysis}

Geostatistical analysis was conducted from maps of ELISA positive plants to study the spatial and temporal spread of ZYMV and WMV in fields of transgenic and nontransgenic plants. Experimental semivariograms were established for both ZYMV and WMV at each sampling date in 1994 and 1995 based on the values of an indicator variable. This approach was used because DASELISA gives positive or negative scores. The indicator variable was defined as:

$I(x)= \begin{cases}1 & \text { for } R\left(x_{i}\right) \geq 2 * C \\ 0 & \text { for } R\left(x_{i}\right)<2 * C\end{cases}$

where $R\left(x_{i}\right)$ is the DAS-ELISA OD $405 \mathrm{~nm}$ reading of a plant at location $\left(x_{i}\right)$ with coordinates $(x, y)$, and $C$ is the DAS-ELISA OD $405 \mathrm{~nm}$ reading for the negative control, i.e., healthy nontransgenic plant. The indicator variable $I\left(x_{i}\right)$ was used for each plant position to establish semivariograms at each sampling date for each genotype and each of the two targeted viruses, i.e., ZYMV and WMV.

The semivariance $\gamma(h)$ was calculated as:

$\gamma(h)=\frac{1}{2 n_{(h)}} * \sum_{i=1}^{n_{(h)}}\left[I\left(x_{i}\right)-I\left(x_{i+h}\right)\right]^{2}$

where $I\left(x_{\mathrm{i}}\right)$ is the measured value of the indicator variable at point $x_{i}$ and $I\left(x_{i+h}\right)$ is the measured sample value of the indicator variable at point $x_{i+h}$ located at a separation distance $(h)$ away from $x_{i}$. The total number of sample pairs for any possible separation distance $(h)$ was $n_{(h)}$, with $(h)$ being limited by the size of the field plot. A separation distance of one $h$ unit $=1 \mathrm{~m}$, the distance between adjacent plants, was used in this study.

Semivariograms were obtained by plotting $\gamma(h)$ versus the separation distance $(h)$. They were used to characterize the spatial dependence of plants that reacted positively in DAS-ELISA, except those in border rows that served as virus source. Experimental semivariograms were plotted and smoothed using the least squares computer program GAMFIT written by Dr. R. Rossi, Washington State University, Pullman, WA. Omidirectional semivariograms calculated with the program SPATCOR (Dr. R. Rossi, Washington State University, Pullman, WA) were obtained by averaging standardized semivariograms in all directions.

The spatial structures and ranges of spatial dependence were compared using standardized semivariograms, which were obtained by dividing $\gamma(h)$ by the population variance $\left(\sigma^{2}\right)$. The shape parameters were estimated by fitting theoretical semivariograms to experimental semivariograms using GAMFIT.

Theoretical models fitted in this study were the spherical $\left\{\gamma(h)=C_{0}+C_{1} *\left[1.5(h / b)-0.5(h / b)^{3}\right]\right\}$, gaussian $\left\{\gamma(h)=C_{0}+C_{1} *\left[1-\operatorname{Exp}(-h / b)^{2}\right]\right\}$, exponential $\left\{\gamma(h)=C_{0}+C_{1} *[1-\operatorname{Exp}(-h / b)]\right\}$, power $\quad\left\{\gamma(h)=C_{0}+C_{1} * h^{2}\right\}, \quad$ and linear $\left\{\gamma(h)=C_{0}+C_{1} * h\right\}$ models, where $C_{0}$ is the nugget, $C_{1}$ the slope for the linear model or the structural variance for the other models, $C_{0}+C_{1}$ the sill, e.g. maximum value for the semivariance, and $b$ the range of spatial dependence. If $a$ semivariogram has a sill and is flat, there is no correlation between sample points because of the occurrence of a random phenomenon designated pure nugget effect $\left[\gamma(h)=C_{0}\right]$ (David 1977).

\section{Screenhouse experiments}

To examine whether symptomatic test plants could serve as virus source for secondary aphidmediated spread and to substantiate the geostatistical analysis of the open field experiments, virus transmission experiments were conducted in screenhouses in 1995. A few test plants in the center of the four field plots, i.e., two plots with transgenic plants, one with $\mathrm{ZW}-20 \mathrm{H}$ and one with ZW-20B, and two plots with nontransgenic plants, were covered late in the growing season (81 dpp) with screenhouses when test plants developed intense localized chlorotic dots and/or blotches and severe systemic symptoms, respectively. Screenhouses measured $6 \times 4 \times 3 \mathrm{~m}$ and covered 8 plants in two adjacent rows. Covered plants 
were heavily sprayed twice with insecticides to eliminate indigenous aphids. Then, healthy nontransgenic squash cv President were transplanted in close spatial proximity to established transgenic or nontransgenic plants inside the screenhouses, and aviruliferous Myzus persicae (approximately 50 per plant) from rearings on chinese cabbage were deposited on symptomatic leaves of test plants at 2-3 day intervals over 18 days. Screenhouses were maintained in the field until the end of the growing season. Plants of virus recipient squash cv President were monitored daily for symptom development and removed from screenhouses as soon as symptoms were visible.

\section{Results}

Resistance of transgenic squash ZW-20 to aphid-mediated transmission of ZYMV and WMV

Transgenic squash ZW-20 plants were established over two consecutive years in small-scale field plots (Fig. 1A, foreground) and subjected to aphid-vectored inoculations of ZYMV and WMV from mechanically inoculated control plants surrounding each plot. Thus, the first and last rows of each plot, as well as the first and last plants of each row, consisted of infected control plants (Fig. 1B and C). This layout simulated field settings where ZYMV and WMV are transmitted from external virus sources into solid blocks of transgenic squash, thereby approaching conditions of natural virus infection in commercial fields of transgenic squash ZW-20. Plots of nontransgenic plants were used as controls (Fig. 1A, background).

In the 1994 and 1995 growing seasons, the majority of transgenic $\mathrm{ZW}-20 \mathrm{H}$ and $\mathrm{ZW}-20 \mathrm{~B}$ plants showed no systemic symptoms upon mixed infection by ZYMV and WMV (Fig. 1D and Fig. 2). However, a number of plants from both transgenic lines developed mild symptoms consisting of chlorotic dots (Fig. 1E) and/or blotches (Fig. 1F) that were mainly confined to old leaves. Both ZYMV and WMV were detected by DASELISA in leaf tissue of transgenic ZW-20H and
ZW-20B plants exhibiting mild symptoms but not in asymptomatic leaf tissues surrounding localized chlorotic dots and blotches (data not shown). At the end of both growing seasons, some transgenic plants reacted positively for ZYMV (9-36\%) and WMV (2-17\%) but the rate of mixed infection by ZYMV and WMV was limited (4-12\%), as shown by DAS-ELISA (Table 1).

Remarkably, the percentage of transgenic plants that exhibited mild symptoms and reacted positively for ZYMV or WMV in DAS-ELISA was extremely low, in particular for those showing mixed infection $[0.7 \%$ ( 1 of 139$)$ of $\mathrm{ZW}-20 \mathrm{H}$ and $11 \%$ (16 of 139) of ZW-20B] in 1995 (Table 2). A chi-square analysis of $2 \times 2$ contingency tables indicated no significant correlation between expression of mild symptoms and serological detection of the two target viruses in transgenic squash $\quad \mathrm{ZW}-20 \mathrm{H} \quad(\mathrm{df}=3 ; \quad P=0.05, \quad F$-statistics $=2.63)$. This feature is explained by the high resistance level to ZYMV and WMV and by the fact that young apical leaves were tested in DASELISA. These were usually symptomless and free of ZYMV and WMV. Interestingly, the correlation between expression of mild symptoms and serological detection of ZYMV and WMV was significant $(\mathrm{df}=3 ; P=0.05 ; F$-statistics $=17.40)$ in transgenic squash ZW-20B, likely because the two target viruses were less restricted in these plants than in transgenic squash $\mathrm{ZW}-20 \mathrm{H}$.

In contrast to transgenic plants, nontransgenic squash exhibited severe systemic symptoms including mosaic, vein yellowing, chlorosis, leaf deformation, shoestringing, and stunted growth in both growing seasons (Fig. 1C and G, and Fig. 2). In 1994, 94\% of the control plants were symptomatic at $57 \mathrm{dpp}$ (Fig. 2A) and $100 \%$ in both fields at $54 \mathrm{dpp}$ in 1995 (Fig. 2B). ZYMV and/or WMV were readily detected in most, if not all, of the control plants $(95-100 \%)$ and the rate of mixed infection was high (57-86\%) at the end of both growing seasons (Table 1).

Three transgenic ZW-20B plants (1 of 143 in 1994 and 2 of 278 in 1995) developed severe systemic mosaic symptoms (Fig. 2), suggesting the presence of one or more untargeted virus(es). Based on previous field trials with cucurbits on the Crittenden farm in Geneva, NY (Fuchs et al. 1998a, b 1999), putative causal agents could be 

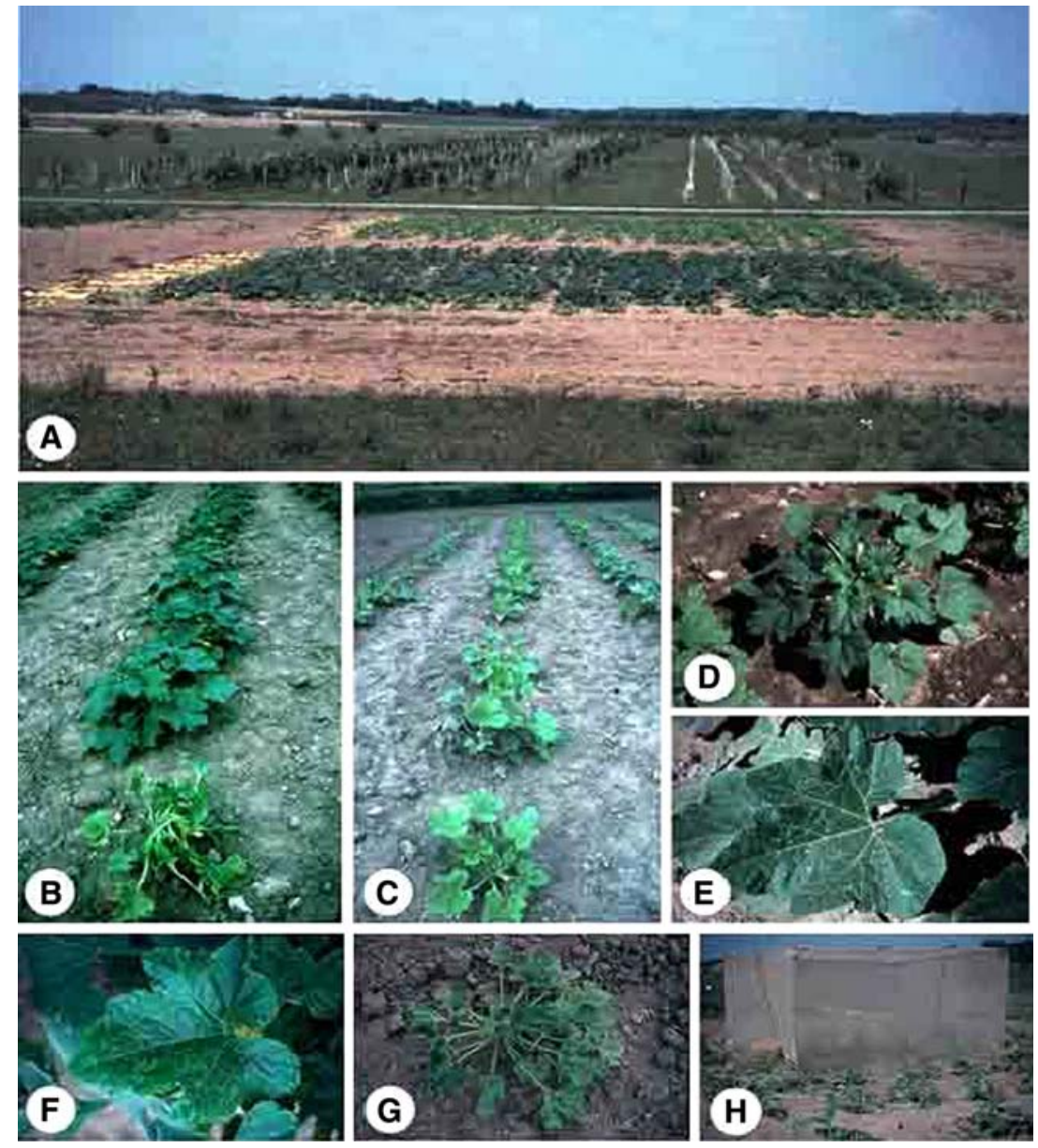

Fig. 1 Reaction of transgenic squash ZW-20H and ZW20B, both expressing the CP genes of ZYMV and WMV, and nontransgenic squash to infection by ZYMV and WMV. (A) Field plots of transgenic squash ZW-20H (foreground) and nontransgenic squash (background), both surrounded by mechanically-inoculated control squash that served as primary virus inocula at $78 \mathrm{dpp}$ in 1995, (B) Close-up of a ZYMV-inoculated border control plant (bottom) and a row of transgenic squash ZW-20B, all

the aphid-borne Papaya Ringspot Virus (PRSV) type w or Cucumber Mosaic Virus, or the nematode-borne Tomato Ringspot Virus or Tobacco Ringspot Virus.

All fruits of transgenic plants remained asymptomatic and of marketable quality throughout the two growing seasons whereas the majority of fruits of nontransgenic plants were symptomatic with discoloration and malformations, and hence, of no marketable value (data not shown). subjected to aphid-mediated virus inoculation, (C) Closeup of a WMV-inoculated border control plant (bottom) and a row of control plants, all subjected to aphidmediated virus inoculation, (D) Asymptomatic transgenic squash ZW-20H, (E), Leaf of transgenic squash ZW-20H exhibiting localized chlorotic dots, (F) Leaf of transgenic squash ZW-20B exhibiting localized chlorotic blotches, (G) Control squash with severe systemic symptoms, and (H) Screenhouse covering squash plants at 86 dpp in 1995

Distinct temporal patterns of ZYMV and WMV in fields of transgenic and nontransgenic squash plants

The temporal patterns of symptomatic transgenic plants were strikingly different from those of symptomatic controls (Fig. 3, six left versus six right panels). Only 4,19 , and $40 \%$ of the transgenic $\mathrm{ZW}-20 \mathrm{H}$ plants developed chlorotic dots at 14, 45, and $74 \mathrm{dpp}$, respectively (Fig. 3B, F, and $\mathrm{J})$, and 11,37 , and $60 \%$ of the transgenic ZW-20B 

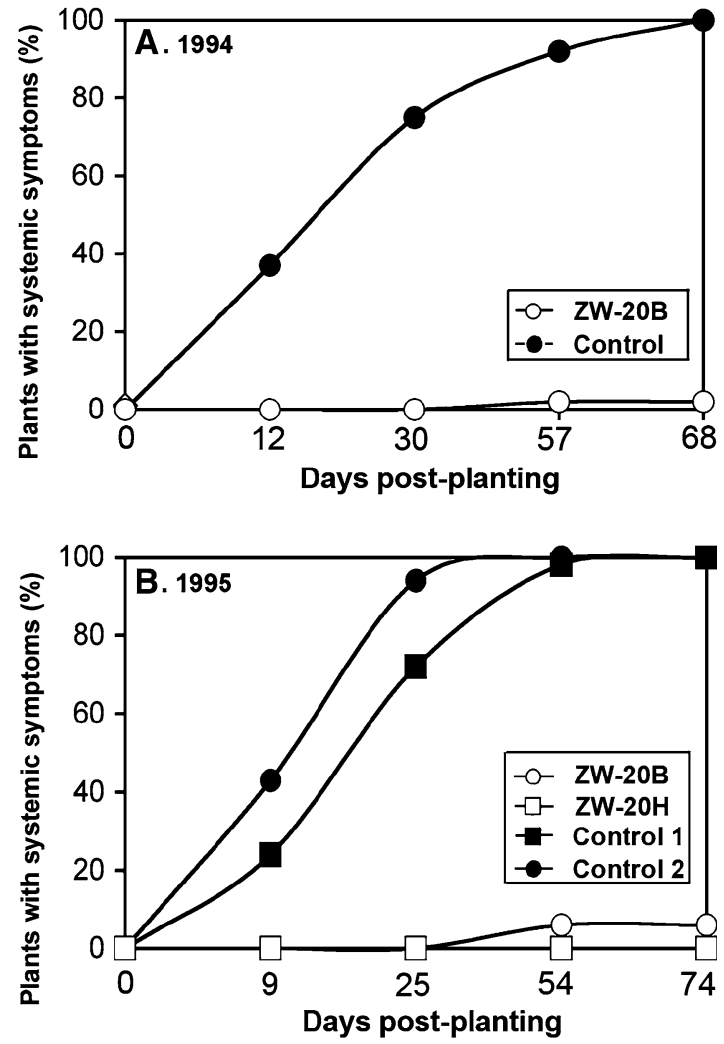

Fig. 2 Disease progress curves on three squash genotypes exposed to aphid-mediated infection by ZYMV and WMV in (A) two field plots planted in 1994, and (B) four field plots planted in 1995 . The squash genotypes tested were nontransgenic commercial cv Pavo and transgenic squash ZW-20H and ZW-20B, both expressing the CP genes of ZYMV and WMV. The cumulative number of plants with systemic symptoms was recorded overtime for each genotype

plants had chlorotic dots and/or blotches at the same dates (Fig. 3A, E and I). In contrast, the percentage of nontransgenic plants with severe systemic symptoms exceeded $50 \%$ at $14 \mathrm{dpp}$ and reached $100 \%$ at $74 \mathrm{dpp}$ (Fig. $3 \mathrm{C}, \mathrm{D}, \mathrm{G}, \mathrm{H}, \mathrm{K}$, and $\mathrm{L})$. Transgenic $\mathrm{ZW}-20 \mathrm{H}$ plants that reacted positively for ZYMV and/or WMV in ELISA were scarce and did not increase in number at the same magnitude as controls (Fig. 3B, F, and J vs. C, G, and K). Similarly, less transgenic ZW-20B plants reacted positively overtime for ZYMV and WMV in ELISA than controls (Fig. 3A, E, and I vs. D, H, and L). Interestingly, the temporal increase of ELISA positive plants was slightly higher for transgenic $\mathrm{ZW}-20 \mathrm{~B}$ than transgenic ZW-20H plants (Fig. 3A, E, and I vs. B, F, and J), substantiating the higher level of resistance of $\mathrm{ZW}-20 \mathrm{H}$ relative to $\mathrm{ZW}-20 \mathrm{~B}$ plants (Tricoli et al. 1995).

The patterns of symptomatic and ELISA positive nontransgenic plants were increasingly dense overtime (Fig. 3C, D, G, H, K, and L). Noteworthy, control plants became infected faster in 1995 than in 1994. For example, 69\% and $99 \%$ of the controls were symptomatic at $25 \mathrm{dpp}$ and $41 \mathrm{dpp}$ in 1995 while only $40 \%$ and $55 \%$ of their 1994 counterparts showed symptoms at $30 \mathrm{dpp}$ and $50 \mathrm{dpp}$ (Fig. 2). ELISA data confirmed the difference in virus incidence between the two growing seasons (Table 1). However, despite a more efficient aphid-vectored virus spread in 1995, the reaction of transgenic ZW20B plants was similar in 1994 and 1995 (Fig. 2 and Table 1).

Distinct omnidirectional spatial patterns of ZYMV and WMV in fields of transgenic and nontransgenic squash plants

The omnidirectional spatial spread of ZYMV and WMV was compared in fields of transgenic and nontransgenic squash plants in 1995. Early in the growing season, test plants, which reacted positively in DAS-ELISA, were essentially clustered near border rows (Fig. 3A-D), suggesting that virus infection likely started from the mechanically inoculated border plants or eventually from virus sources outside of the field plots (Fig. 3A and D). However, transgenic and control plants had subsequently strikingly distinct spatial patterns: Scarce vs. uniformly dense (Fig. 3, six left versus six right panels). Nontransgenic plants in the center of the field plots became rapidly infected, reaching almost $100 \%$ at 45 dpp (Fig. 3G and $\mathrm{H})$.

Experimental and theoretical semivariograms were developed for transgenic and nontransgenic plants that reacted positively for ZYMV or WMV in DAS-ELISA in 1994 and 1995. Data obtained late in both growing seasons, i.e., $68 \mathrm{dpp}$ in 1994 and 74 dpp in 1995, are summarized in Fig. 4. For most transgenic squash ZW-20H and ZW-20B, semivariograms describing the spatial structure of ZYMV (Fig. 4I) and WMV (Fig. 4B, F and J) were poorly structured, either completely flat or 
Table 1 Incidence of ZYMV and WMV in fields of transgenic and nontransgenic squash upon aphid-mediated infection over two consecutive years

\begin{tabular}{|c|c|c|c|c|c|c|c|c|c|}
\hline \multirow[t]{2}{*}{ Genotype $^{\mathrm{a}}$} & \multirow[t]{2}{*}{ Virus } & \multicolumn{4}{|c|}{ ELISA positive plants in $1994^{\mathrm{c}}(\%)$} & \multicolumn{4}{|c|}{ ELISA positive plants in $1995^{\mathrm{c}}(\%)$} \\
\hline & & $N^{\mathrm{b}}$ & $(29 \mathrm{dpp})^{\mathrm{d}}$ & (45 dpp) & $(68 \mathrm{dpp})$ & $N$ & $(14 \mathrm{dpp})$ & $(45 \mathrm{dpp})$ & $(74 \mathrm{dpp})$ \\
\hline \multirow[t]{3}{*}{$\mathrm{ZW}-20 \mathrm{H}$} & $\mathrm{Z}$ & na & & & & 139 & 1 & 6 & 9 \\
\hline & $\mathrm{W}$ & & & & & & 2 & 2 & 2 \\
\hline & $\mathrm{Z}+\mathrm{W}$ & & & & & & 1 & 2 & 4 \\
\hline \multirow[t]{3}{*}{ Control } & $\mathrm{Z}$ & na & & & & 139 & 36 & 21 & 14 \\
\hline & $\mathrm{W}$ & & & & & & 10 & 7 & 0 \\
\hline & $\mathrm{Z}+\mathrm{W}$ & & & & & & 11 & 63 & 86 \\
\hline \multirow[t]{3}{*}{ ZW-20B } & $\mathrm{Z}$ & 143 & 18 & 18 & 36 & 139 & 4 & 4 & 11 \\
\hline & W & & $\mathrm{nt}$ & 8 & 12 & & 0 & 17 & 17 \\
\hline & $\mathrm{Z}+\mathrm{W}$ & & na & 2 & 12 & & 0 & 1 & 9 \\
\hline \multirow[t]{3}{*}{ Control } & $\mathrm{Z}$ & 140 & 66 & 78 & 36 & 142 & 25 & 57 & 30 \\
\hline & W & & $\mathrm{nt}$ & 1 & 5 & & 2 & 6 & 4 \\
\hline & $\mathrm{Z}+\mathrm{W}$ & & na & 17 & 57 & & 1 & 20 & 61 \\
\hline
\end{tabular}

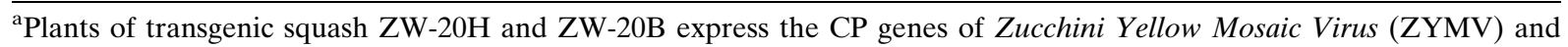
Watermelon Mosaic Virus (WMV)

${ }^{\mathrm{b}}$ Number of plants tested per genotype; $\mathrm{nt}=$ not tested; na = not applicable

${ }^{\mathrm{c} C u m u l a t i v e}$ percentage of plants that reacted positively for (Z) ZYMV, (W) WMV, or (Z + W) ZYMV and WMV in DAS-ELISA. Plants were scored as positive if their DAS-ELISA OD $405 \mathrm{~nm}$ values were at least twice those of nontransgenic controls; nt: not tested

${ }^{\mathrm{d}}$ Days post-planting (dpp)

Table 2 Incidence of localized mild symptoms and detection of ZYMV and WMV by DAS-ELISA in transgenic squash at 74 dpp in 1995

\begin{tabular}{|c|c|c|c|c|c|c|}
\hline \multirow[t]{2}{*}{ ELISA $^{a}$} & \multicolumn{3}{|c|}{$\mathrm{ZW}-20 \mathrm{H}^{\mathrm{b}}$} & \multicolumn{3}{|c|}{ ZW-20B } \\
\hline & AS & MS & Total & AS & MS & Total \\
\hline 0 & 82 & 35 & 117 & 54 & 25 & 79 \\
\hline Z & 7 & 3 & 10 & 8 & 8 & 16 \\
\hline W & 2 & 4 & 6 & 17 & 7 & 24 \\
\hline $\mathrm{Z}+\mathrm{W}$ & 5 & 1 & 6 & 4 & 16 & 20 \\
\hline Total & 96 & 43 & 139 & 83 & 56 & 139 \\
\hline
\end{tabular}

${ }^{\mathrm{a}}$ Data represent the number of plants that reacted (0) negatively or positively for $(\mathrm{Z}) \mathrm{ZYMV},(\mathrm{W}) \mathrm{WMV}$, or $(\mathrm{Z}+\mathrm{W})$ ZYMV and WMV in DAS-ELISA. Plants were scored as positive if their DAS-ELISA OD $405 \mathrm{~nm}$ values were at least twice those of healthy nontransgenic controls

${ }^{\mathrm{b}}$ Asymptomatic (AS) plants and plants exhibiting mild symptoms (MS), which consisted of chlorotic dots and/or blotches, were discriminated. Transgenic squash ZW-20H and ZW-20B express the CP genes of ZYMV and WMV

oscillating throughout the two growing seasons. These results suggested a lack of spatial dependence among most transgenic plants and no plantto-plant virus spread. However, a well-structured semivariogram characterized the spread of ZYMV in transgenic squash ZW-20B in 1994 (Fig. 4A), revealing the potential occurrence of some extent of plant-to-plant spread of ZYMV in ZW-20B when virus incidence was high (Table 3). The slightly increasing semivariogram for ZYMV
Fig. 3 Spatial spread of ZYMV and WMV overtime in transgenic and nontransgenic squash during the 1995 growing season. Row numbers and plant position are indicated on the $x$ and $y$ axes, respectively, for each of the four field plots. Test plants with no symptoms and negative reactions to ZYMV and/or WMV in ELISA (open squares), localized mild symptoms and negative reactions to ZYMV and/or WMV in ELISA (light grey squares), localized mild symptoms and positive reactions to ZYMV and/or WMV in ELISA (dark grey squares), and severe systemic symptoms and positive reactions to ZYMV and/or WMV in ELISA (black squares) are mapped at 14, 45, and 74 dpp. $x=$ dead plant 
Transgenic ZW-20B Transgenic ZW-20H
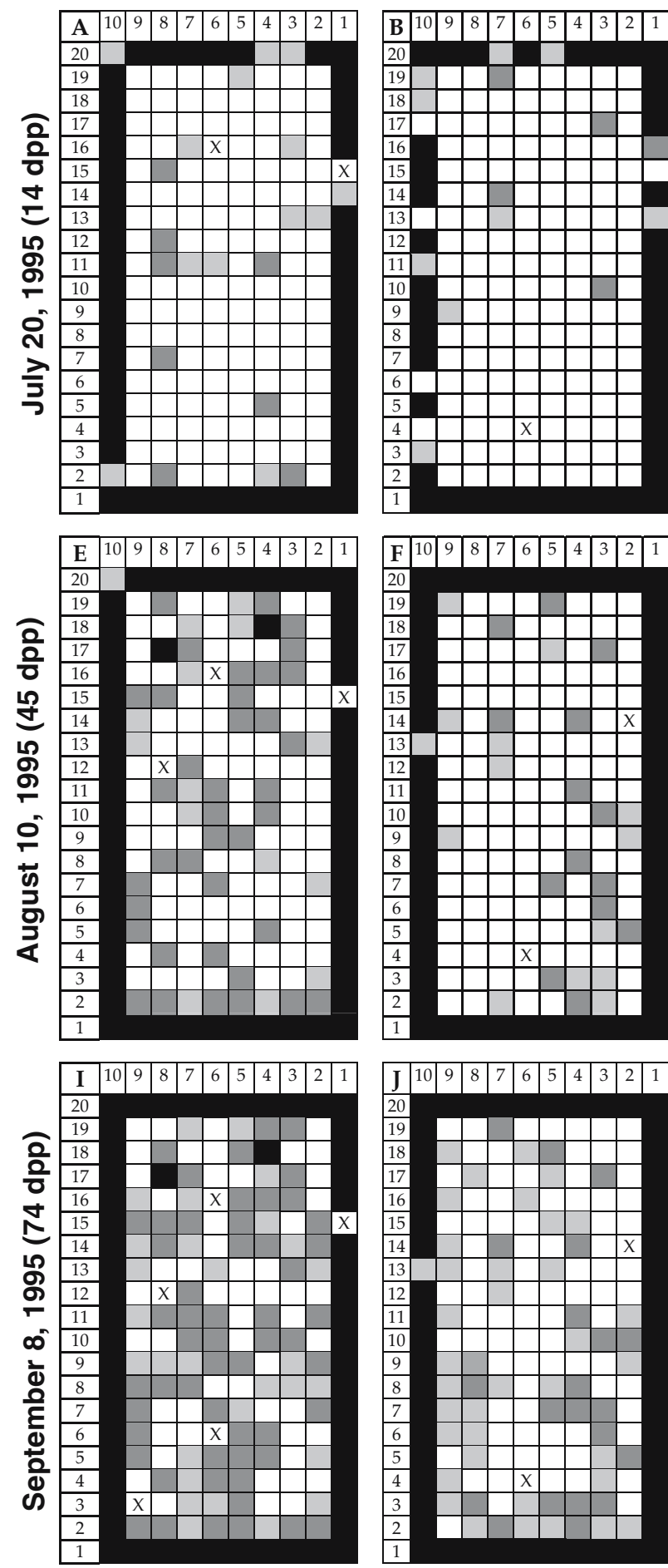
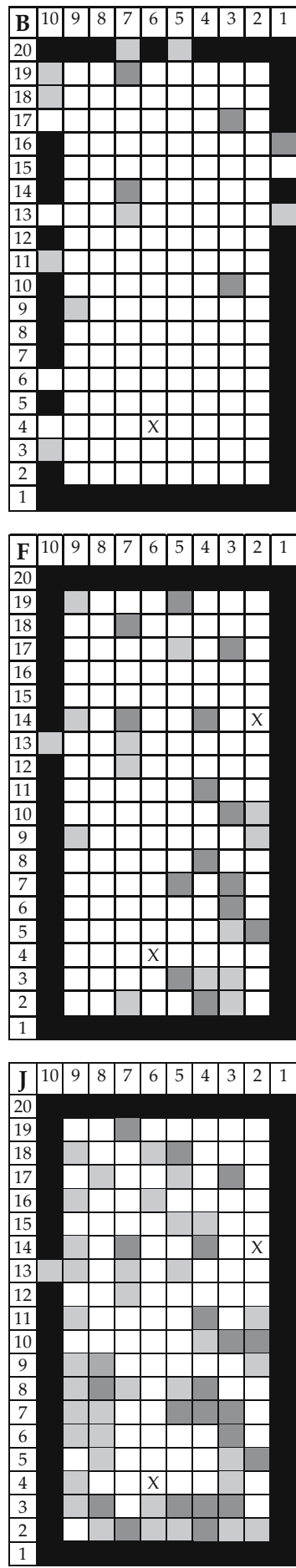

Control 1
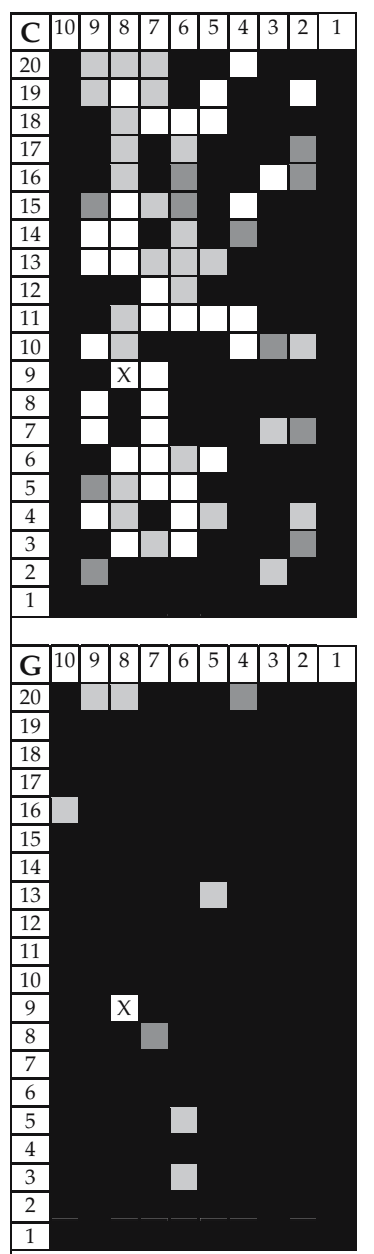

Control 2
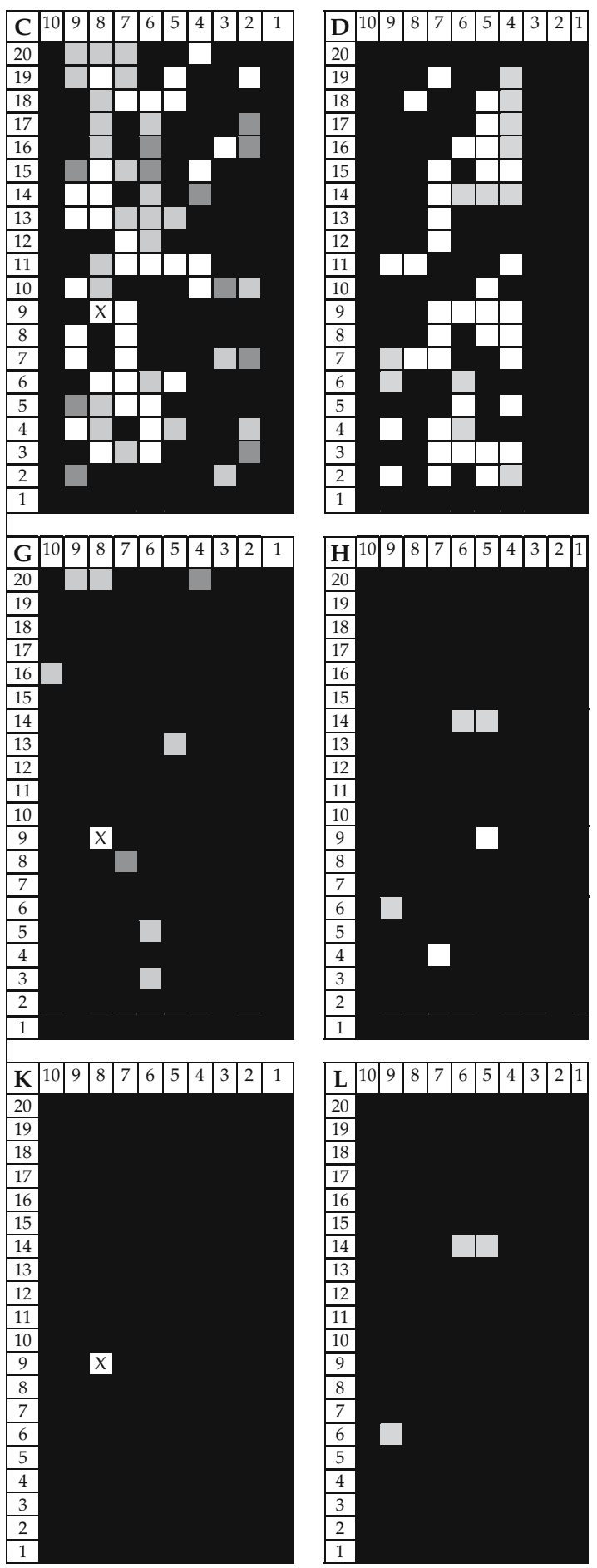


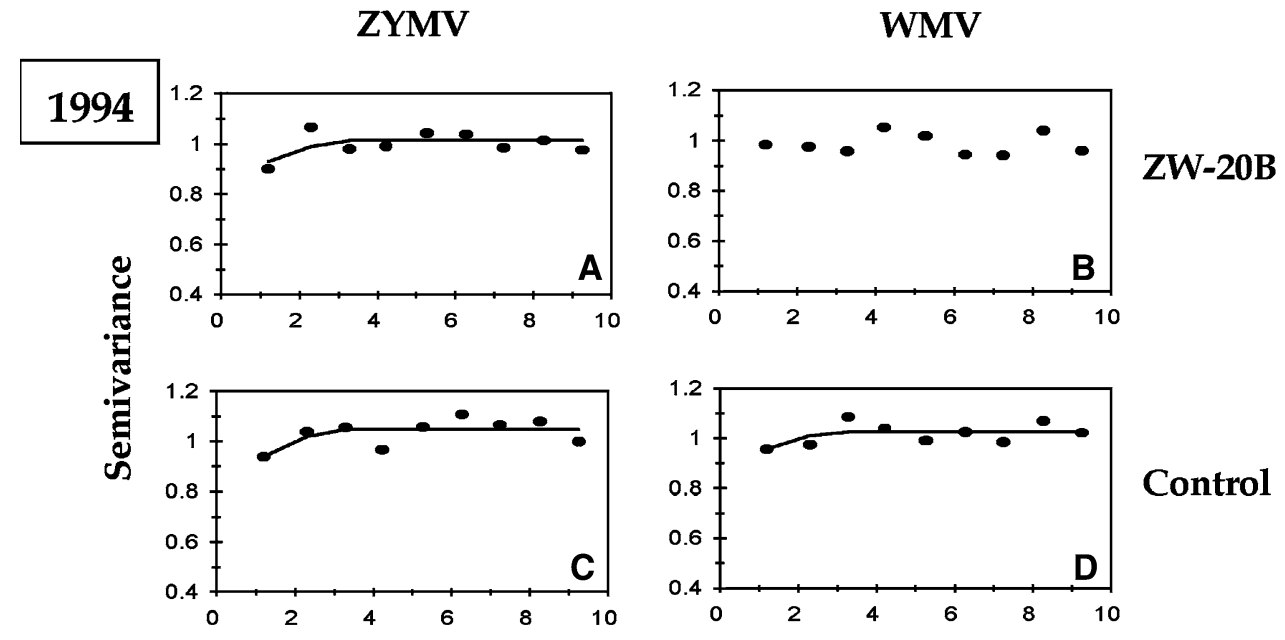

Distance between plants (m)
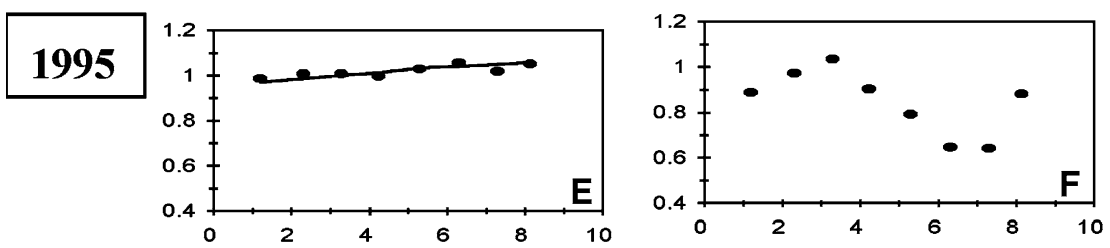

ZW-20H
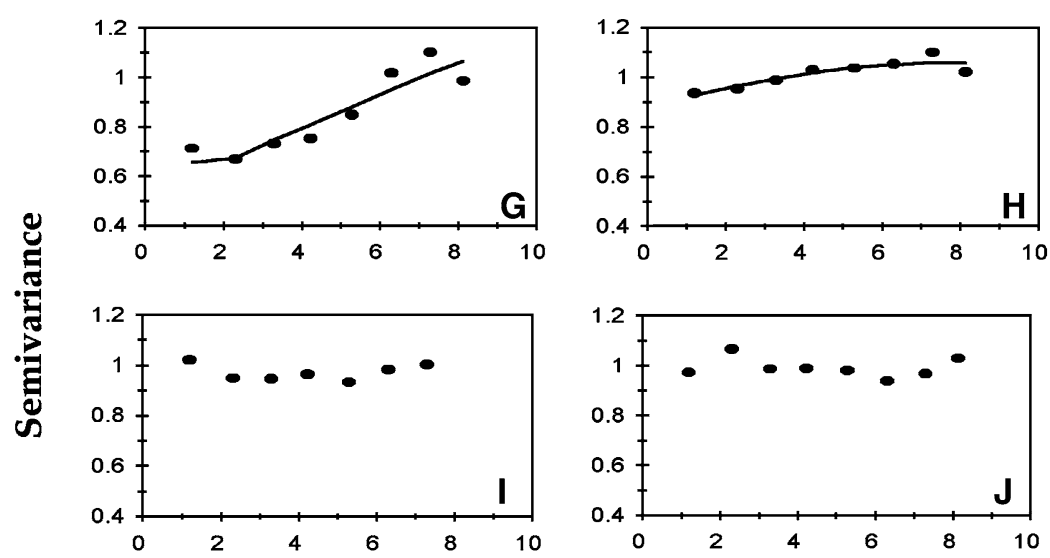

\section{Control 1}

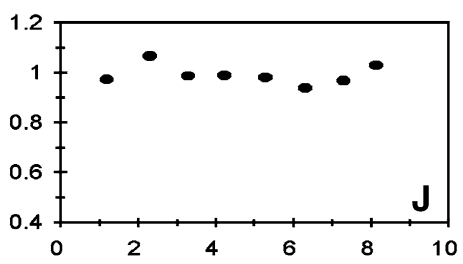

ZW-20B
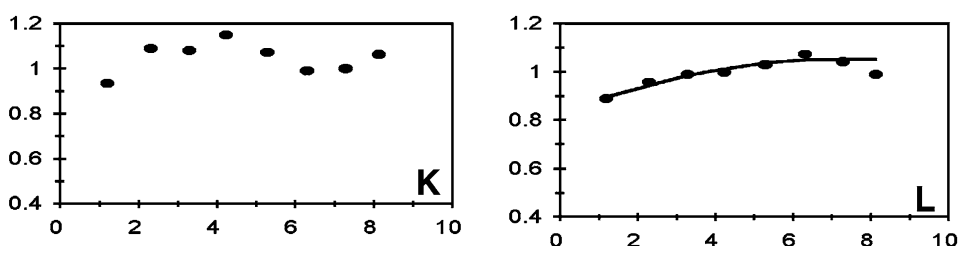

Control 2

Fig. 4 Standardized semivariograms of transgenic and nontransgenic squash plants that reacted positively for ZYMV and WMV in ELISA at (1994) 68 dpp in 1994 and (1995) $74 \mathrm{dpp}$ in 1995. The genotypes tested were transgenic squash ZW-20H and ZW-20B, both expressing

the CP genes of ZYMV and WMV, and nontransgenic control cv Pavo. Experimental (black dots) and fitted (black line) theoretical spherical semivariograms are presented. Lines are drawn only if fitting to the spherical model was significant at $P \leq 0.05$ 
Table 3 Estimated omnidirectional semivariogram parameters for the spherical model at three sampling dates in 1994 and 1995

\begin{tabular}{|c|c|c|c|c|c|c|c|c|c|c|c|c|}
\hline \multirow[t]{2}{*}{ Year } & \multirow[t]{2}{*}{ Genotype $^{a}$} & \multirow[t]{2}{*}{ Sampling date ${ }^{b}$} & \multicolumn{5}{|l|}{$\mathrm{ZYMV}^{\mathrm{c}}$} & \multicolumn{5}{|l|}{ WMV } \\
\hline & & & Incidence & $R^{2}$ & Nugget & Sill & Range & Incidence & $R^{2}$ & Nugget & Sill & Range \\
\hline \multirow[t]{6}{*}{1994} & \multirow[t]{3}{*}{ ZW-20B } & 29 & 0.18 & $0.86^{*}$ & 0.60 & 1.09 & 5.83 & $\mathrm{nt}$ & na & na & na & na \\
\hline & & 45 & 0.20 & $0.85 *$ & 0.79 & 1.15 & 6.44 & 0.10 & 0.00 & 1.14 & 0.95 & 584 \\
\hline & & 68 & 0.48 & $0.53 *$ & 0.59 & 1.02 & 3.23 & 0.24 & 0.07 & 0.97 & 1.13 & 85.5 \\
\hline & \multirow[t]{3}{*}{ Control } & 29 & 0.66 & 0.00 & 0.28 & 1.01 & 0.72 & $\mathrm{nt}$ & na & na & na & na \\
\hline & & 45 & 0.95 & $0.78 *$ & 0.78 & 1.07 & 6.39 & 0.18 & 0.01 & 0.58 & 1.00 & 1.57 \\
\hline & & 68 & 0.93 & $0.51 *$ & 0.77 & 1.05 & 2.91 & 0.62 & $0.47 *$ & 0.88 & 1.02 & 3.51 \\
\hline \multirow[t]{12}{*}{1995} & \multirow[t]{3}{*}{$\mathrm{ZW}-20 \mathrm{H}$} & 14 & 0.02 & 0.15 & 1.11 & 1.21 & 6.07 & 0.03 & 0.44 & 1.15 & 0.85 & 3.44 \\
\hline & & 45 & 0.08 & 0.23 & 0.73 & 1.02 & 2.24 & 0.04 & 0.00 & 0.59 & 0.87 & 2.46 \\
\hline & & 74 & 0.13 & $0.66^{*}$ & 0.98 & 1.07 & 15.42 & 0.06 & 0.00 & 0.59 & 0.87 & 2.46 \\
\hline & \multirow[t]{3}{*}{ Control 1} & 14 & 0.47 & $0.63^{*}$ & 0.89 & 1.03 & 6.64 & 0.21 & $0.57 *$ & 0.44 & 1.00 & 2.28 \\
\hline & & 45 & 0.84 & 0.01 & 0.56 & 0.96 & 1.34 & 0.70 & 0.41 & 1.15 & 0.98 & 2.24 \\
\hline & & 74 & 1.00 & $0.85^{*}$ & 0.64 & 1.25 & 7.49 & 0.86 & $0.83^{*}$ & 0.89 & 1.06 & 7.44 \\
\hline & \multirow[t]{3}{*}{ ZW-20B } & 14 & 0.04 & 0.34 & 1.14 & 0.97 & 3.40 & 0.00 & na & na & na & na \\
\hline & & 45 & 0.05 & 0.11 & 0.52 & 1.02 & 1.20 & 0.18 & 0.12 & 0.45 & 1.01 & 1.68 \\
\hline & & 74 & 0.20 & 0.00 & 0.79 & 0.95 & 0.00 & 0.26 & 0.04 & 0.46 & 0.99 & 1.44 \\
\hline & \multirow[t]{3}{*}{ Control 2} & 14 & 0.26 & 0.35 & 1.24 & 0.97 & 2.24 & 0.03 & 0.35 & 1.22 & 0.97 & 2.30 \\
\hline & & 45 & 0.77 & 0.22 & 0.83 & 1.08 & 2.88 & 0.26 & 0.11 & 0.96 & 1.50 & 1.80 \\
\hline & & 74 & 0.91 & 0.44 & 0.49 & 1.07 & 2.09 & 0.65 & $0.95^{*}$ & 0.84 & 1.05 & 6.83 \\
\hline
\end{tabular}

${ }^{\mathrm{a}}$ Genotypes were transgenic squash ZW-20H and ZW-20B, both expressing the CP genes of ZYMV and WMV, and the nontransgenic squash cv Pavo (control)

${ }^{\mathrm{b}}$ Sampling dates are indicated as days post-planting

${ }^{\mathrm{c}}$ Incidence: rate of plant infection by ZYMV or WMV; $R^{2}$ : model fitting ; Nugget: $\mathrm{C}_{0}$; Sill: $C_{0}+C_{1}$; Range: (b) range of spatial dependence (in meters) for the spherical model $\left\{\gamma(h)=C_{O}+C_{1}{ }^{*}\left[1.5(h / b)-0.5(h / b)^{3}\right]\right\}$; nt: not tested; na: not applicable; (*) Significant at $P \leq 0.05$

in transgenic ZW-20H in 1995 (Fig. 4E) suggested some extent of long distance influx of this virus, and therefore no plant-to-plant spread within the experimental plot.

In contrast to transgenic plants, well-structured semivariograms characterized the spread of ZYMV (Fig. 4C and G) and WMV (Fig. 4D, H, and L) in most nontransgenic plants late in 1994 and 1995 when disease incidence was high (Table 3). These results indicated a strong spatial dependence among infected control plants, and therefore, an efficient plant-to-plant spread of ZYMV and WMV. Similarly, semivariograms were well structured when disease incidence was lower earlier in both years (Table 3), substantiating some spatial dependence on virus spread, although a few semivariograms were poorly structured or flat. An oscillating semivariogram described the spread of ZYMV in control 2 (Fig. 4K) with high virus incidence (0.91), indicating a random structure. This may be a consequence of reduced spatial variability when
ZYMV epidemic progressed and disease incidence increased, as shown for downy mildew in cabbage (Stein et al. 1994).

Characterization of spatial structures by semivariogram parameters

Among the five theoretical semivariogram models fitted to the experimental data, the spherical model was the most appropriate to study and characterize spatial dependence on spread of ZYMV and WMV within the limits of our field plots. Therefore, the estimated omnidirectional semivariogram parameters are summarized for the spherical model in Table 3.

For transgenic squash ZW-20H and ZW-20B plants, the spherical model fitted very poorly the spatial structure of ZYMV and WMV spread $(P \leq 0.05)$, revealing limited, if any, spatial dependence on virus spread. The only exceptions were for ZYMV in transgenic ZW-20B squash $\left(0.53 \leq R^{2} \leq 0.86\right)$ (Table 3) in 1994 (Fig. 4A) 
and in transgenic $\mathrm{ZW}-20 \mathrm{H}$ squash $\left(R^{2}=0.66\right.$ at $74 \mathrm{dpp}$ ) (Table 3) in 1995 (Fig. 4E). For the latter, however, the low spatial dependence $(0.08)$ with a long range of spatial dependence $(15.42 \mathrm{~m})$ (Table 3) suggested an influx of ZYMV from external sources or border rows because the range value is beyond the dimensions of the field plot.

For nontransgenic control squash, the spherical model fitted well the spatial structure of ZYMV spread at mid (45 dpp) $\left(R^{2}=0.78\right)$ and late season (68 dpp) $\left(R^{2}=0.51\right)$ in 1994 (Fig. 4C) $(P \leq 0.05)$ with ranges of spatial dependence of $6.39 \mathrm{~m}$ and $2.91 \mathrm{~m}$, respectively (Table 3 ). A similar situation was found in the early and late 1995 season (Fig. 4G) in one of the two fields (Control $1 ; R^{2}=0.63$ and 0.85 , respectively) (Table 3). Also, the spherical model fitted the spatial structure of WMV spread in nontransgenic squash in 1995 with high $R^{2}$ values (0.83 in Control 1 and 0.95 in Control 2) (Fig. $4 \mathrm{H}$ and L) and ranges of spatial dependence of $7.44 \mathrm{~m}$ and $6.83 \mathrm{~m}$, respectively (Table 3 ).

Altogether, the model fitting analysis was consistent primarily with plant-to-plant virus spread in nontransgenic but not in transgenic squash ZW-20H.

\section{Screenhouse experiments}

We examined whether transgenic plants with localized mild symptoms could serve as virus source for secondary Myzus persicae-mediated spread of ZYMV and WMV to healthy recipient nontransgenic squash in screenhouses (Fig. 1H). At this developmental stage, transgenic $\mathrm{ZW}-20 \mathrm{H}$ and ZW-20B plants exhibited localized chlorotic dots (Fig. 1E) and/or blotches (Fig. 1F), nontransgenic plants developed severe systemic mosaic (Fig. 1G), and mixed infection was high, especially in control plants (Table 1).

None of the virus recipient squash plants $(0 \%$, 0 of 24) became symptomatic in the screenhouse covering transgenic $\mathrm{ZW}-20 \mathrm{H}$ plants (Table 4). In contrast, $100 \%$ (67 of 67 ) of the recipient squash plants became symptomatic in the two screenhouses covering nontransgenic plants (Table 4). These results indicated that Myzus persicae efficiently transmitted viruses from symptomatic nontransgenic plants but not from symptomatic
Table 4 Transmissibility of ZYMV and WMV by Myzus persicae from symptomatic transgenic and nontransgenic squash

\begin{tabular}{lll}
\hline Screenhouse $^{\text {a }}$ & $\begin{array}{l}\text { Donor } \\
\text { squash }^{\mathrm{b}}\end{array}$ & $\begin{array}{l}\text { No symptomatic/ } \\
\text { No tested }^{\mathrm{c}}\end{array}$ \\
\hline 1 & ZW-20H & $0 / 24$ \\
2 & ZW-20B & $14 / 38$ \\
3 & Control 1 & $32 / 32$ \\
4 & Control 2 & $35 / 35$ \\
\hline
\end{tabular}

${ }^{\text {a Screenhouses covering } 8 \text { test plants were established in }}$ the field at $81 \mathrm{dpp}$ in 1995 . Screenhouses 1 and 4 covered transgenic squash ZW-20B and ZW-20H, respectively, and screenhouses 2 and 3 covered nontransgenic plants

${ }^{\mathrm{b}}$ Transgenic squash ZW-20H and ZW-20B exhibited mild symptoms consisting of localized chlorotic dots and/or blotches, and nontransgenic squash exhibited severe systemic symptoms of mosaic and deformation upon aphidmediated transmission of ZYMV and/or WMV

${ }^{\mathrm{c}}$ Data represent the number of symptomatic recipients over the total number of recipients tested. Recipient plants were healthy nontransgenic squash cv President that were randomly interspaced between test plants

transgenic ZW-20H plants. Notwithstanding, a limited number of recipient squash became symptomatic in the screenhouse covering transgenic ZW-20B plants (37\%, 14 of 38) (Table 4).

\section{Discussion}

Transgenic crookneck squash ZW-20H and ZW20B exhibited high levels of resistance to aphidmediated mixed infection by ZYMV and WMV in commercial-type small-scale field settings, confirming previous reports (Arce-Ochoa et al. 1995; Clough and Hamm 1995; Fuchs and Gonsalves 1995; Tricoli et al. 1995). Our geostatistical analyses further revealed distinct spatial patterns overtime of the ZYMV and WMV spread in fields of transgenic and nontransgenic plants. First, experimental semivariograms were flat or had no clear structure for plants of transgenic line ZW$20 \mathrm{H}$, indicating a random spatial relationship and no spatial dependence on virus spread. Although some transgenic $\mathrm{ZW}-20 \mathrm{H}$ plants developed localized mild symptoms (chlorotic dots) upon infection by ZYMV and WMV, our analyses suggested that they did not serve as virus source for secondary spread. In contrast, in many cases for nontransgenic plants, experimental 
semivariograms were well structured and fitted well a spherical model, indicating a strong spatial dependence on virus spread among susceptible control plants. As a consequence, control plants could serve as virus source for secondary spread. Results from aphid transmission experiments in screenhouses confirmed these hypotheses since transgenic squash $\mathrm{ZW}-20 \mathrm{H}$ did not serve as virus source for secondary spread while nontransgenic controls efficiently did. For plants of transgenic line ZW-20B, some extent of plant-to-plant virus spread was predicted and actually shown to occur in screenhouses. Thus, transgenic squash ZW-20B could serve as virus source for secondary aphidmediated spread, although with a much lower efficiency than controls. This explains a similarly well-structured semivariogram for the spread of ZYMV in ZW-20B (Fig. 4A) and control squash (Fig. 4C) in 1994, in spite of a marked difference in ZYMV incidence (0.48 vs. 0.93 ).

The differential impact of transgenic squash ZW-20H and ZW-20B on virus spread could be explained by the higher level of resistance to ZYMV and WMV of the former. It is also likely that the percentage of recipient plants that became infected by viruliferous aphids in the $\mathrm{ZW}$ 20B screenhouse was artificially high because large numbers of aphids were introduced periodically at short intervals onto leaves showing mild symptoms. This is, to the best of our knowledge, the first study on the impact of transgenic squash ZW-20 on the temporal and spatial dynamics of ZYMV and WMV spread. It is also the first to report on the fact that a commercial virus-resistant transgenic crop (ZW-20H) does not serve as virus source for secondary aphid-mediated transmission.

The transgenic squash $\mathrm{ZW}-20 \mathrm{H}$ used in this study was cultivar Freedom II, the first virus- and disease-resistant transgenic crop deregulated in the United States (Medley 1994). The reaction of this cultivar to ZYMV and WMV infection is of epidemiological importance. Transgenic squash ZW-20H efficiently limited the incidence of ZYMV and WMV by restricting the amount of infected tissue, and reducing the availability of virus inoculum for acquisition and subsequent secondary spread by aphid vectors. Thus, spread of the two target viruses was limited. Since epidemics of ZYMV and WMV are severely limited in transgenic squash $\mathrm{ZW}-20 \mathrm{H}$, it is reasonable to anticipate a reduction in the incidence of ZYMV and WMV in susceptible crops that grow in close spatial proximity to commercial fields of transgenic squash $\mathrm{ZW}-20 \mathrm{H}$.

The temporal and spatial spread of Soybean Mosaic Virus (SMV) was recently quantified in fields of transgenic and nontransgenic soybeans (Steinlage et al. 2002). Transgenic lines 3-24 and 7B-11 delayed the onset of disease by 10-29 days, and reduced the rate of SMV infection and seed transmission. The potential of SMV-infected transgenic plants to serve as virus source for secondary spread could not be assessed because nontransgenic and transgenic plants were interspaced.

Aphid-vectored spread occurred more readily for ZYMV than for WMV although the same number of virus source plants was used in all field plots. Several hypotheses could account for this differential spread. Among these is a differential titer between the two viruses, the behavior of aphid vectors, and the occurrence of hetero-encapsidation or phenotype mixing in favor of ZYMV. Also, Lecoq and Pitrat (1985) previously showed that ZYMV was transmitted more efficiently than WMV in virus mixtures, suggesting that the helper component of WMV can provide epidemiological advantages for the spread of ZYMV.

Our study has significant implications in environmental risk assessment of commercial transgenic squash $\mathrm{ZW}-20 \mathrm{H}$ and cultivars derived thereof. One of the environmental safety issues expressed over virus-resistant transgenic crops containing viral $\mathrm{CP}$ genes relies on the encapsidation of genomic RNAs of viruses challenging transgenic plants by the $\mathrm{CP}$ subunits expressed from the $\mathrm{CP}$ transgene (Fuchs and Gonsalves 1997; Tepfer 2002). A possible consequence of this phenomenon, designated as heterologous encapsidation, is that changes in virus-vector specificity might occur. For example, an initially aphid nontransmissible virus or viral strain could become aphid transmissible by interacting with CP subunits expressed by a CP transgene derived from an aphid transmissible virus or viral strain. The fact that transgenic squash $\mathrm{ZW}-20 \mathrm{H}$, which is 
not immune to ZYMV and WMV, does not serve as virus reservoirs for secondary spread of ZYMV and WMV suggests that it is unlikely to induce changes in virus-vector specificity through heterologous encapsidation. Therefore, it seems reasonable to predict that transgenic squash $\mathrm{ZW}-20 \mathrm{H}$, and any cultivar derived thereof, which displays a similarly high level of resistance against ZYMV and WMV, is unlikely to efficiently assist the transmission of aphid nontransmissible strains of ZYMV and WMV through heterologous encapsidation, unless challenge viruses overcome the engineered resistance. Previously, we showed that the aphid nontransmissible strain MV of ZYMV was transmitted in fields of transgenic squash expressing the CP gene of an aphid transmissible strain of WMV (Fuchs et al. 1999). However, the transmission rate was very low (2\%) and more importantly, epidemics of ZYMV strain MV did not develop despite the availability of numerous transgenic plants and conditions of high disease pressure. On the other hand, changes in virus-vector specificity were not observed in transgenic squash and melon plants expressing the CP gene of an aphid transmissible strain of CMV (Fuchs et al., 1998a, b). This study and our earlier work (Fuchs et al., 1998a, b, 1999) indicate that transgenic cucurbits expressing CP genes seem to have limited impact on the environment beyond those of natural background events.

Acknowledgements We are grateful to D. M. Tricoli from the Asgrow Seed Company for providing us with seeds of transgenic and nontransgenic squash. We thank Sheri Ecker-Day, Dave Hummer, and Vânia Souza for their excellent help, and Daniel Jarecke. This work was partially supported by a competitive grant from USDA's Biotechnology Risk Assessment Grant Program (No 9533120-1878). We also thank Dr. L.M. Yepes for critically reading the manuscript, and Drs. J.C. Zadoks and L.V. Madden for initial comments.

\section{References}

Arce-Ochoa JP, Dainello F, Pike LM, Drews D (1995) Field performance comparison of two transgenic summer squash hybrids to their parental hybrid line. HortScience 30:492-493

Blancard D, Lecoq H, Pitrat M (2004) A colour atlas of cucurbit diseases: observation, identification and control. Wiley and Sons, New York, NY, p 304
Camann MA, Culbreath AK, Todd JW, Demski JW (1995) Spatial and temporal patterns of spotted wilt epidemics in peanut. Phytopathology 85:879-885

Castle SJ, Perring TM, Farrar CA, Kishaba AN (1992) Field and laboratory transmission of watermelon mosaic virus 2 and zucchini yellow mosaic virus by various aphid species. Phytopathology 82:235-240

Chellemi DO, Rohrbach KG, Yost RS, Sonoda RM (1988) Analysis of the spatial pattern of plant pathogens and diseased plants using geostatistics. Phytopathology 78:221-226

Clough GH, Hamm PB (1995) Coat protein transgenic resistance to watermelon mosaic virus and zucchini yellow mosaic virus in squash and cantaloupe. Plant Dis 79:1107-1109

David M (1977) Developments in geomathematics 2. Geostatistical ore reserve estimation. Elsevier, Amsterdam, p 364

Davis RF, Mizuki MK (1987) Detection of cucurbit viruses in New Jersey. Plant Dis 71:40-44

Fuchs M, Gonsalves D (1995) Resistance of transgenic hybrid squash ZW-20 expressing the coat protein genes of zucchini yellow mosaic virus and watermelon mosaic virus 2 to mixed infections of both potyviruses. Bio/Technology 13:1466-1473

Fuchs M, Gonsalves D (1997) Genetic engineering. In: Rechcigl NA, Rechcigl JE (eds) Environmentally safe approaches to crop disease control. Lewis Publishers/ CRC Press, Boca Raton, FL, pp 333-368

Fuchs M, Klas FE, McFerson JR, Gonsalves D (1998a) Transgenic melon and squash expressing coat protein genes of aphid-borne viruses do not assist the spread of an aphid non-transmissible strain of cucumber mosaic virus. Trans Res 7:449-462

Fuchs M, Tricoli DM, Carney KJ, Schesser M, McFerson JR, Gonsalves D (1998b) Comparative virus resistance and fruit yield of transgenic squash with single and multiple coat protein genes. Plant Dis 82: 1350-1356

Fuchs M, Gal-On A, Raccah B, Gonsalves D (1999) Epidemiology of an aphid nontransmissible potyvirus in fields of nontransgenic and coat protein transgenic squash. Transg Res 99:429-439

Gonsalves D, Chee P, Provvidenti R, Seem R, Slightom JL (1992) Comparison of coat protein-mediated and genetically-derived resistance in cucumbers to infection by cucumber mosaic virus under field conditions with natural challenge inoculations by vectors. Bio/ Technology 10:1562-1570

Gottwald TR (1992a). LCOR2-Spatial correlation analysis software for the personal computer. Plant Dis 76: 213-215

Gottwald TR (1992b) Spatial and spatio-temporal autocorrelation analysis of citrus canker epidemics in nurseries and groves in Argentina. Phytopathology 82:843-851

Gray SM, Moyer JW, Bloomfield P (1986) Two-dimensional distance class model for quantitative description of virus-infected plant distribution lattices. Phytopathology 76:243-247 
Habili N, Nutter FW (1997) Temporal and spatial analysis of grapevine leafroll-associated virus 3 in Pinot noir grapevines in Australia. Plant Dis 81:625-628

Journel AG (1987) Geostatistics for the Environmental Sciences. Project No CR 811893 Applied Earth Science Department, Stanford University, Stanford, CA, 94305

Kanieswki W, Lawson C, Sammons B, Haley L, Hart J, Delanay X, Tumer NE (1990) Field resistance of transgenic Russett Burbank potato to effects of infection by potato virus $\mathrm{X}$ and potato virus $\mathrm{Y}$. Bio/ Technology 8:750-754

Larkin RP, Gumpertz ML, Ristaino J (1995) Geostatistical analysis of Phytophthora. Epidemic development in commercial bell pepper fields. Phytopathology 85:191-203

Lecoustre R, Fargette D, Fauquet C, de Reffye P (1989) Analysis and mapping of the spatial spread of African cassava mosaic virus using geostatistics and kriging the technique. Phytopathology 79:913-920

Lecoq H, Pitrat M (1985) Specificity of the helper component-mediated aphid transmission of three potyviruses infecting muskmelon. Phytopathology 75:890893

Madden LV, Pirone TP, Raccah B (1987) Analysis of spatial patterns of virus-diseased tobacco plants. Phytopathology 77:1409-1417

Malnoe P, Farinelli L, Collet GF, Reust W (1994) Smallscale field tests with transgenic potato cv. Bintje to test resistance to primary and secondary infections with potato virus Y. Plant Mol Biol 25:963-975
Medley TL (1994) Availability of determination of nonregulated status for virus resistant squash. Fed Regist 59:64187-64189

Reynolds KM, Madden LV, Ellis MA (1988) Spatio-temporal analysis of epidemic development of leather rot of strawberry. Phytopathology 78:246-252

Stein A, Kocks CG, Zadoks JC, Frinking HD, Ruissen MA, Meyers DE (1994) A geostatistical analysis of the spatio-temporal development of downy mildew epidemics in cabbage. Phytopathology 84:1227-1239

Steinlage TA, Hill JH, Nutter FW (2002) Temporal and spatial spread of Soybean mosaic virus (SMV) in soybeans transformed with the coat protein gene of SMV. Phytopathology 92:478-486

Tanne E, Marcus R, Dubitzky E, Raccah B (1996) Analysis of progress and spatial pattern of corky bark in grapes. Plant Dis 84:1227-1239

Tepfer M (2002) Risk assessment of virus-resistant transgenic plants. Annu Rev Phytopathol 40:467-491

Tricoli D, Carney KJ, Russell PF, McMaster JR, Groff DW, Hadden KC, Himmel PT, Hubbard JP, Boeshore ML, Quemada HD (1995). Field evaluation of transgenic squash containing single or multiple virus coat protein gene constructs for resistance to cucumber mosaic virus, watermelon mosaic virus 2 and zucchini yellow mosaic virus. Bio/Technology 13:1458-1465

Ullman DE, Cho JJ, German TL (1991) Occurrence and distribution of cucurbit viruses in the Hawaiian Islands. Plant Dis 75:367-370

Zitter TA, Hopkins DL, Thomas CE (1996) Compendium of cucurbit diseases. APS Press, St Paul, MN 